\title{
The Influence of the Barrier Layer on SST Response during Tropical Cyclone Wind Forcing Using Idealized Experiments
}

\author{
JoHna E. Rudzin, Lynn K. SHAY, AND WILliam E. JOHNS \\ Department of Ocean Sciences, Rosenstiel School of Marine and Atmospheric Science, University of Miami, Miami, Florida
}

(Manuscript received 2 January 2018, in final form 3 April 2018)

\begin{abstract}
Multiple studies have shown that reduced sea surface temperature (SST) cooling occurs under tropical cyclones (TCs) where a fresh surface layer and subsurface halocline exist. Reduced SST cooling in these scenarios has been attributed to a barrier layer, an upper-ocean feature in the tropical global oceans in which a halocline resides within the isothermal mixed layer. Because upper-ocean stratification theoretically reduces ocean mixing induced by winds, the barrier layer is thought to reduce SST cooling during TC passage, sustaining heat and moisture fluxes into the storm. This research examines how both the inclusion of salinity and upper-ocean salinity stratification influences SST cooling for a variety of upper-ocean thermal regimes using one-dimensional (1D) ocean mixed layer (OML) models. The Kraus-Turner, Price-Weller-Pinkel, and Pollard-Rhines-Thompson 1D OML schemes are used to examine SST cooling and OML deepening during $30 \mathrm{~m} \mathrm{~s}^{-1}$ wind forcing $(\sim$ category 1 TC) for both temperature-only and temperature-salinity stratification cases. Generally, the inclusion of salinity (a barrier layer) reduces SST cooling for all temperature regimes. However, results suggest that SST cooling sensitivities exist depending on thermal regime, salinity stratification, and the 1D OML model used. Upper-ocean thermal and haline characteristics are put into context of SST cooling with the creation of a barrier layer baroclinic wave speed to emphasize the influence of salinity stratification on upper-ocean response under TC wind forcing.
\end{abstract}

\section{Introduction}

A halocline within the isothermal layer exists within several basins, including the tropical Atlantic and Pacific Oceans, the Indian Ocean, and the Caribbean Sea, creating a barrier layer (BL) (Sprintall and Tomczak 1992). This layer aids in the suppression of turbulent heat flux from the thermocline to the air-sea interface, affecting air-sea fluxes (Lukas and Lindstrom 1991; McPhaden and Foltz 2013; Mignot et al. 2012; Chi et al. 2014). The role of BLs on air-sea exchanges is important to understand since numerous tropical cyclones (TCs) pass through BL regions and air-sea exchanges that influence TC intensity are based on the upper-ocean dynamics that occur.

Literature has shown that the BL impacts sea surface temperature (SST) response during TC wind forcing via reduced mixing efficiency (Wang et al. 2011; Neetu et al. 2012; Balaguru et al. 2012; Grodsky et al. 2012; Vissa et al. 2013; Reul et al. 2014; Androulidakis et al. 2016; Hernandez et al. 2016; Rudzin et al. 2017; Yan et al. 2017).

\footnotetext{
Corresponding author: Johna E. Rudzin, jrudzin@rsmas.miami.
} edu
However, the dynamics behind BL erosion during TC wind forcing has not been studied in detail in the available literature. Hernandez et al. (2016) briefly examined the impact of the BL on SST response in context of differing thermal and haline regimes. Yet, their goal was not to examine the upper-ocean dynamics that contribute to SST response. Yan et al. (2017) investigated mixed layer dynamics that leads to BL erosion but only examined these processes using one type of mixed layer model. Hence, an understanding of different processes that influence $\mathrm{BL}$ erosion is missing.

Upper-ocean dynamics are important to understand since modest SST differences during a TC have been shown to dramatically influence air-sea heat and moisture transfer (Cione and Uhlhorn 2003; Jaimes et al. 2015, 2016). Hence, if SST response is misrepresented in a BL environment within coupled numerical forecast models, this could lead to errors in air-sea transfer and potentially forecasted TC intensity. To address the gaps from previous literature, several one-dimensional (1D) mixed layer model experiments are analyzed to investigate how the inclusion of salinity in different thermal regimes impacts the SST response. BL erosion time is estimated to assess the resilience of the upper-ocean thermal and 
haline structure to each mixing scheme. The use of several mixing schemes highlights how individual upperocean processes, such as shear-induced mixing and instantaneous wind erosion, influence SST response. The findings are put in context of a BL baroclinic wave speed to understand how a stratified upper ocean influences ocean coupling during TC passage.

\section{Data and methods}

Six different temperature profiles and two salinity profiles from Rudzin et al. (2017) are selected to highlight mixing sensitivity between differing ocean regimes commonly found in the Caribbean Sea, a basin with frequent TCs and subsiding BL. These temperature and salinity profiles were measured in September 2014 within the eastern Caribbean Sea under ambient atmospheric conditions. Temperature profiles represent a warm-core eddy (WCE) (Figs. 1a,b), the Caribbean Current (CC) background flow (Figs. 1c,d), and the Amazon-Orinoco River plume (PLUME) (Figs. 1e,f). The two salinity profiles are selected to represent a strong (Figs. 1a,c,e; strong $S$ ) and weak (Figs. 1b,d,f; weak $S$ ) halocline in the isothermal layer to identify how stratification strength affects SST response.

\section{a. Mixing schemes}

The 1D mixing schemes used are the Kraus-Turner (KT) (Kraus and Turner 1967), Price-Weller-Pinkel (PWP) (Price et al. 1986), and Pollard-RhinesThompson (PRT) mixing schemes (Pollard et al. 1973). Entrainment occurs in KT via instantaneous wind erosion, whereas PRT mixes through shear-induced currents at the base of the mixed layer. PWP implements buoyancy fluxes and shear-induced mixing. The main difference between KT, PRT, and PWP is that PRT and PWP use dynamic instability criteria to mix based on buoyancy and current shear whereas KT does not. Dynamic instability criteria are based on the bulk Richardson number (mixed layer stability) for PRT and both bulk and gradient Richardson numbers (shear flow stability) for PWP. In PRT and PWP, Earth's rotation restores flow stability and eventually causes mixing to cease within an inertial period (IP).

KT and PRT schemes are used on two types of experiments: temperature-only ( $T$ only) experiments (using only temperature from WCE, CC, and PLUME) and temperature-salinity $(T-S)$ experiments that consider both temperature and salinity profiles. PWP only considers $T-S$ experiments since the scheme originally considers density. The former mixing schemes usually consider only temperature but are modified to also examine both temperature and salinity (section $2 \mathrm{~b}$ and the appendix).
For all experiments, total heat flux $Q$ is set to zero to isolate the SST response that is due solely to wind forcing. A latitude of $15^{\circ} \mathrm{N}$ is used to calculate the Coriolis parameter. This latitude is used since the profiles were measured in the Caribbean Sea. Simulations are run out to $0.5 \mathrm{IP}$, equivalent to $24 \mathrm{~h}$ at $15^{\circ} \mathrm{N}$. Wind stress is estimated using the bulk aerodynamic formula $\left(\tau=\rho_{\text {air }} C_{D} U_{10}^{2}\right.$, where $\rho_{\text {air }}$ is air density, $C_{D}$ is the drag coefficient, and $U_{10}$ is the $10-\mathrm{m}$ wind speed) using Powell et al. (2003) drag coefficients with $U_{10}=$ $30 \mathrm{~m} \mathrm{~s}^{-1}$, equivalent to a minimal category-1 hurricane. Wind stress is constant over the entire simulation period. Stronger degrees of hurricane intensity were tested (category 2-5; not shown) but yielded a similar trend (albeit stronger magnitudes) to results presented within this study.

\section{b. Definition and calculation of upper-ocean layers}

Changes to KT and PRT are made so that density is accounted for in the entrainment schemes for $T-S$ experiments (appendix). Initial mixed layer depth (MLD) is calculated following Sprintall and Tomczak (1992) and de Boyer Montegut et al. (2007) accounting for both salinity and temperature, where the MLD is the depth where potential density $\sigma_{\theta}$ is equal to

$$
\Delta \sigma_{\theta}=\sigma_{\Theta}\left(T_{0}-\Delta T, S_{0}\right)-\sigma_{\Theta}\left(T_{0}, S_{0}\right),
$$

where $T_{0}$ and $S_{0}$ are temperature and salinity at the reference depth of $2 \mathrm{~m}$ (Rudzin et al. 2017) and $\Delta T$ is $0.5^{\circ} \mathrm{C}$. The isothermal layer depth (ILD) is the depth at which the temperature is $0.5^{\circ} \mathrm{C}$ less than the SST. The difference between the ILD and MLD is referred to as the barrier layer thickness (BLT).

The initial mixing depth $h_{0}$ for $T-S$ experiments is initialized at $h_{0}=$ MLD whereas $h_{0}=$ ILD for $T$-only experiments such that density is only a function of temperature. For $T$-only experiments, SST cooling will begin immediately since $h_{0}$ is at the ILD. For $T-S$ experiments, SST cooling will not occur until mixing has penetrated to the ILD from the MLD. Mixing in these experiments must erode the $\mathrm{BL}$ and the erosion time and cooling depend on the BLT.

\section{Results and discussion}

\section{a. Inclusion of salinity and stratification strength}

Less SST cooling occurs with the inclusion of salinity in all mixing schemes (Table 1). The difference in cooling between $T$-only and $T-S$ experiments depends on both the thermal regime and the mixing scheme. The KT scheme leads to the largest differences in SST cooling between $T$-only and $T-S$ experiments, with differences ranging from $0.5^{\circ}$ to $6.6^{\circ} \mathrm{C}$ (Table 1 ). 

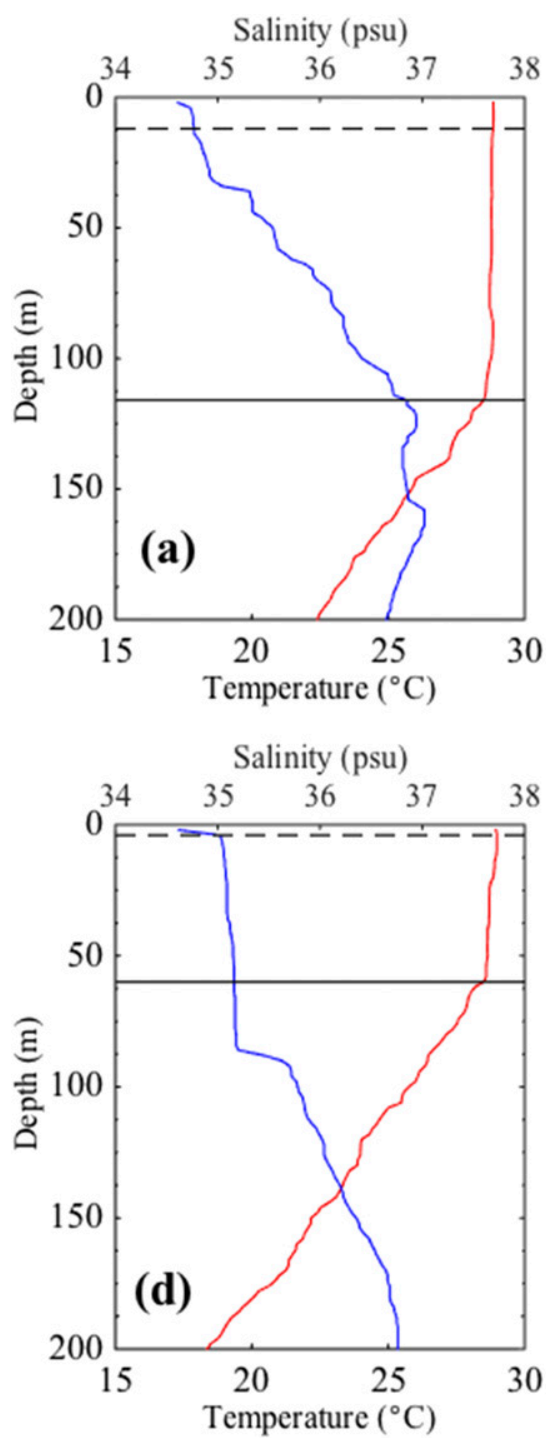
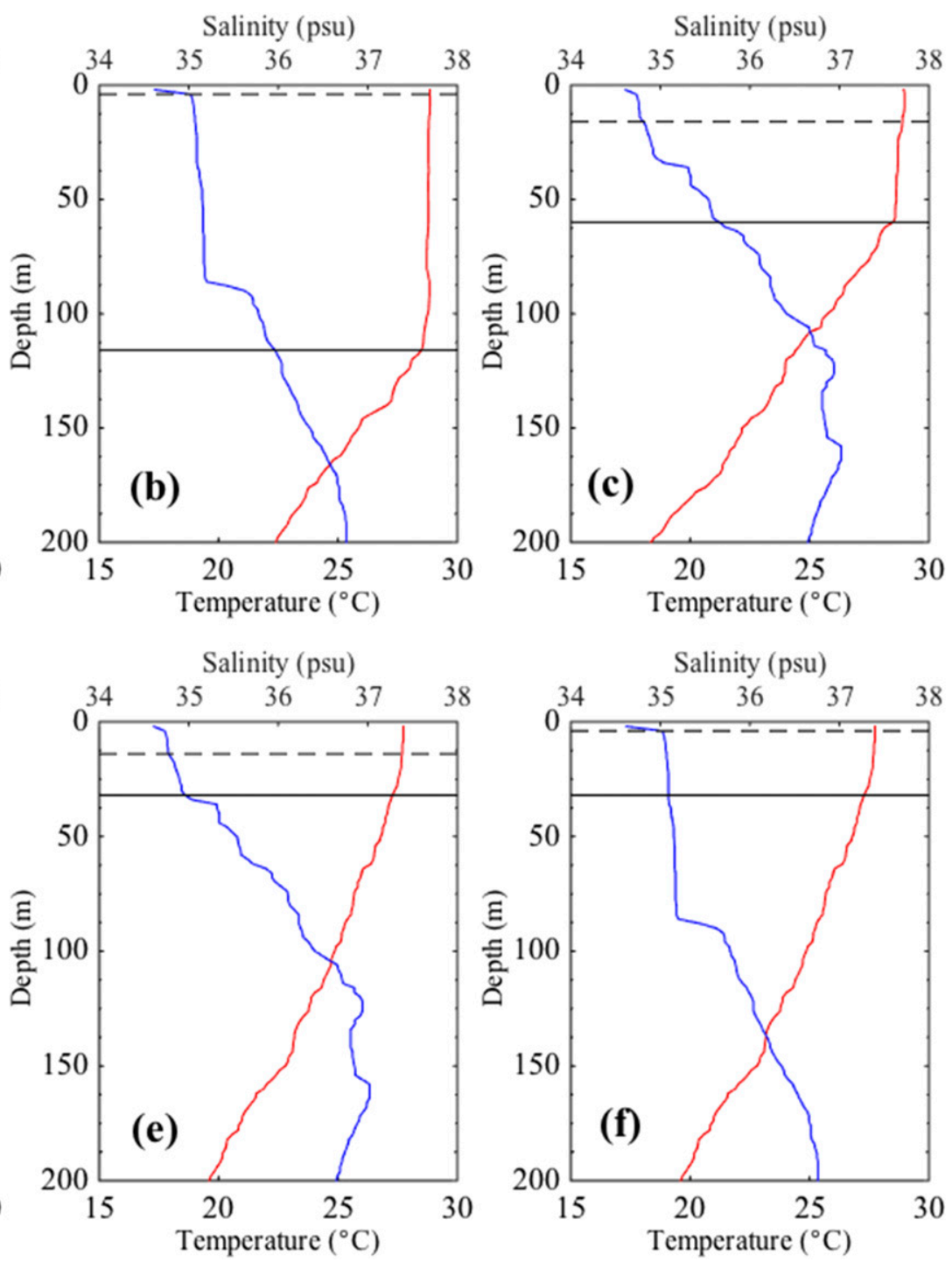

FIG. 1. Temperature (red) and salinity (blue) profiles used in 1D mixed layer models. (a),(b) The WCE regime. (c),(d) The CC regime. (e),(f) The PLUME regime. The dashed black line represents the MLD [Eq. (1)], whereas the solid black line represents the ILD.

Differences in SST cooling between $T$-only and $T-S$ experiments for PRT range from $0.1^{\circ}$ to $1.3^{\circ} \mathrm{C}$. These cooling differences arise because of the extra time for the modeled processes to erode the BL. BL erosion time is defined as the time when the MLD = ILD and SST cooling commences. KT mixing (mechanical wind stirring) takes the longest to erode the $\mathrm{BL}$ compared to shear-induced processes such as PRT and PWP; PWP processes result in the least time (Table 1). This indicates that instantaneous wind erosion (from KT) is the most sensitive mixing process to the inclusion of salinity such that increased stratification reduces the efficiency of wind erosion compared to shear-induced currents. Shear-induced currents (as in PRT and PWP) cut through the stratification more efficiently than the former processes. For example, Fig. 2 highlights the evolution of BL erosion for the PLUME strong $S$ regime using PWP. SST cooling begins within $3 \mathrm{~h}$ of TC wind forcing, caused by increased mixed layer shear eroding the BL. Since PWP uses both mixed layer stability and shear flow instability criteria, BL erosion initiates the quickest between the schemes compared to PRT, which only uses a mixed layer stability criterion. Although KT processes take longer to erode the BL, they have a more efficient cooling rate than shear-induced processes as in PRT and PWP.

The PLUME regime is most sensitive to the inclusion of salinity (largest cooling differences between $T$-only and $T-S)$, whereas the WCE regime has the smallest differences. Similar results were found in Hernandez et al. (2016) 
TABLE 1. Sea surface temperature cooling $\left({ }^{\circ} \mathrm{C}\right)$ and barrier layer erosion time (h) of $1 \mathrm{D}$ mixing experiments using profiles from Fig. 1. Simulations are run to $1 / 2 \mathrm{IP}(\sim 24 \mathrm{~h})$ to estimate $\Delta$ SST. The $T$-only experiments only have one value for each $S$ experiment since $T$-only experiments do not use salinity. An "N" under barrier layer erosion time indicates that barrier layer did not erode.

\begin{tabular}{|c|c|c|c|c|c|c|c|c|}
\hline & \multicolumn{3}{|c|}{$T-S \Delta \operatorname{SST}\left({ }^{\circ} \mathrm{C}\right)$} & \multicolumn{2}{|c|}{$T$-only $\Delta \mathrm{SST}\left({ }^{\circ} \mathrm{C}\right)$} & \multicolumn{3}{|c|}{ Barrier layer erosion time (h) } \\
\hline & KT & PRT & PWP & KT & PRT & KT & PRT & PWP \\
\hline WCE strong $S$ & 0 & 0 & 0 & 0.5 & 0.1 & $\mathrm{~N}$ & $\mathrm{~N}$ & $\mathrm{~N}$ \\
\hline WCE weak $S$ & 0 & 0 & 0 & & & $\mathrm{~N}$ & $\mathrm{~N}$ & $\mathrm{~N}$ \\
\hline CC strong $S$ & 0 & 0 & 0.4 & 2.0 & 1.0 & $\mathrm{~N}$ & $\mathrm{~N}$ & 3.2 \\
\hline CC weak $S$ & 0 & 0.3 & 0.5 & & & $\mathrm{~N}$ & 7.6 & 3.0 \\
\hline PLUME strong $S$ & 0 & 0.3 & 0.7 & 7.0 & 2.0 & $\mathrm{~N}$ & 2.2 & 3.0 \\
\hline PLUME weak $S$ & 0.4 & 0.6 & 0.8 & & & 13.7 & 0.6 & 2.4 \\
\hline
\end{tabular}

where the authors showed that cyclone-induced SST cooling decreases with increasing BLT and increasing salinity stratification. Additionally, the PLUME thermal regime is also most sensitive to the strength of salinity stratification compared to other thermal regimes. This is attributed to the PLUME thermal regime having a shallower ILD relative to other regimes in this study, and, therefore, entrainment of thermocline waters would take less time compared to deeper ILDs. Interestingly, the shallow isothermal $(\sim 30 \mathrm{~m})$ PLUME strong $S$ regime has minimal difference in SST cooling compared to that for the deeper isothermal $(\sim 60 \mathrm{~m}) \mathrm{CC}$
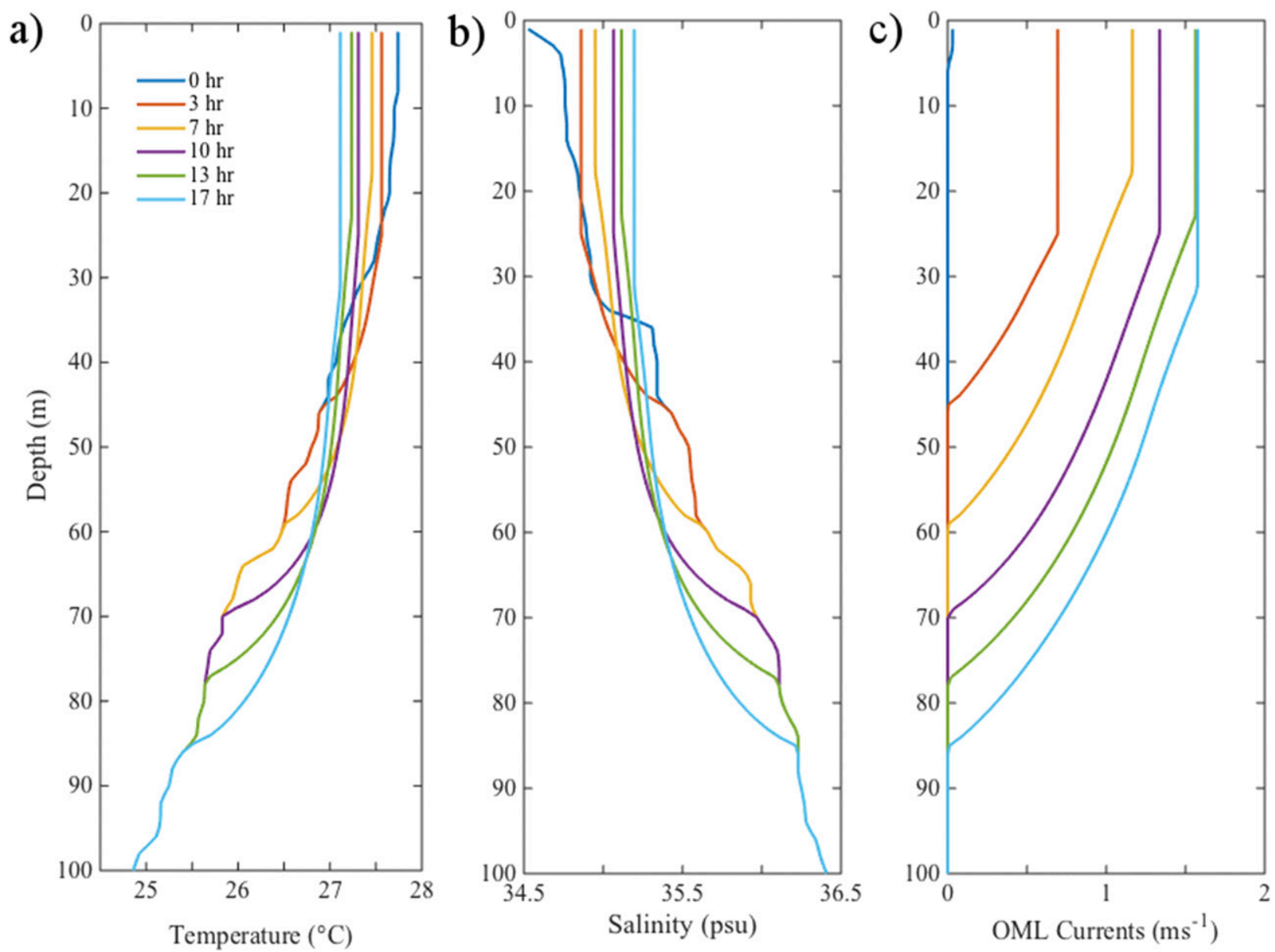

FIG. 2. Time evolution (h) of (a) temperature, (b) salinity, and (c) OML currents for PLUME strong $S$ using the PWP (Price et al. 1986) model. 


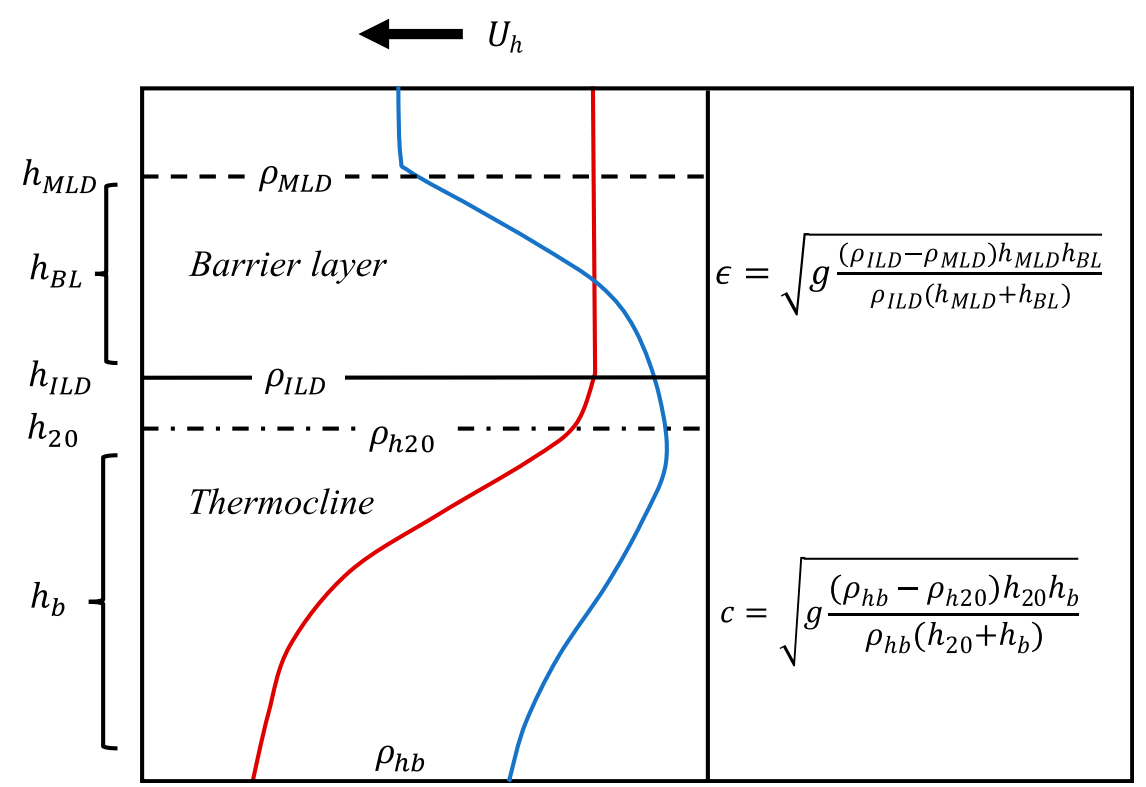

FIG. 3. Schematic of vertical ocean structure depicting the barrier layer and its wave speed $\epsilon$, and the thermocline and its wave speed $c$. The $c$ is calculated by differencing the density between the $20^{\circ} \mathrm{C}$ isotherm $\left(\rho_{h_{20}}\right)$ (proxy for thermocline) and the profile bottom $\rho_{h_{b}}$, where $h_{20}$ is the depth of the $20^{\circ} \mathrm{C}$ isotherm and $h_{b}$ is the thickness between $h_{20}$ and the profile bottom. Temperature is indicated by the red line, whereas salinity is indicated by the blue line. Thicknesses are indicated by brackets. MLD, ILD, and the depth of the $20^{\circ} \mathrm{C}$ isotherm are indicated by the dashed, solid, and dashed-dotted lines, respectively.

weak $S$ regime (Table 1). This suggests salinity stratification in the PLUME strong $S$ regime is reducing mixing efficiency to the point that the SST response is like that of deeper thermal structure.

\section{b. SST response in context of a BL baroclinic wave speed $\epsilon$}

During the passage of a TC, evidence exists that shows the excitement of baroclinic waves within the thermocline via the transfer of wind-driven momentum, inducing shear at the base of the mixed layer (Shay et al. 1998; Shay and Uhlhorn 2008; Jaimes and Shay 2009). The SST response that is expected from this process during TC passage is obtained through the Froude number (Geisler 1970). The Froude number $\left(\mathrm{Fr}=U_{h} c^{-1}\right)$ is the ratio between the storm translation speed $U_{h}$ and the first baroclinic wave phase speed within the thermocline $c$ (Fig. 3). However, Fr only indicates the SST response based on the thermocline and does not consider the density gradient within the BL. Since Fr aids in understanding the upper-ocean/SST response during TC passage, the influence of BL structure on this response needs to be accounted for within the estimation of Fr. Thus, a BL baroclinic wave phase speed $\epsilon$ [Eq. (2)] is created to modify the thermocline baroclinic wave speed in the denominator of Fr and to contextualize the findings in section $3 a$. The resultant number is deemed the stratification
Froude number $\mathrm{Fr}_{s}$ [Eq. (3)]. As shown in section 3a, the stratification in the BL essentially acts as a buffer by reducing the transfer of wind-induced momentum to the thermocline. Hence, the wave speed $\epsilon$, superimposed onto $c$, acts to reduce the baroclinic wave speed within the thermocline, reducing the coupling between the thermocline and the sea surface response (Fig. 3). The $\epsilon$ is estimated by differencing the density between the ILD $\left(\rho_{\text {ILD }}\right)$ and the MLD $\left(\rho_{\text {MLD }}\right)$, where $h_{\mathrm{MLD}}=\mathrm{MLD}$ and $h_{\mathrm{BL}}=\mathrm{BLT}$, and $g$ is the gravitational constant [Eq. (2)]:

$$
\begin{aligned}
\epsilon & =\sqrt{g \frac{\left(\rho_{\mathrm{ILD}}-\rho_{\mathrm{MLD}}\right) h_{\mathrm{MLD}} h_{\mathrm{BL}}}{\rho_{\mathrm{ILD}}\left(h_{\mathrm{MLD}}+h_{\mathrm{BL}}\right)}}, \text { and } \\
\mathrm{Fr}_{s} & =\frac{U_{h}}{c-\epsilon} .
\end{aligned}
$$

For areas that do not have a BL and MLD $=$ ILD, $\epsilon=0$ and $\mathrm{Fr}_{s}=$ Fr. Figure 4 shows $\epsilon$ as a function of SST cooling for the six given regimes and three mixing schemes. To increase the sample size of the experiments within this study, 10 randomly generated temperature and salinity profiles (mean $=0 ; \mathrm{std}=0.25^{\circ} \mathrm{C}$ and $0.1 \mathrm{psu}$ ) for each $T-S$ experiment were run through each mixing scheme to ensure that the findings for the base cases presented in Fig. 4 are robust. Figure 4 indicates that BL 


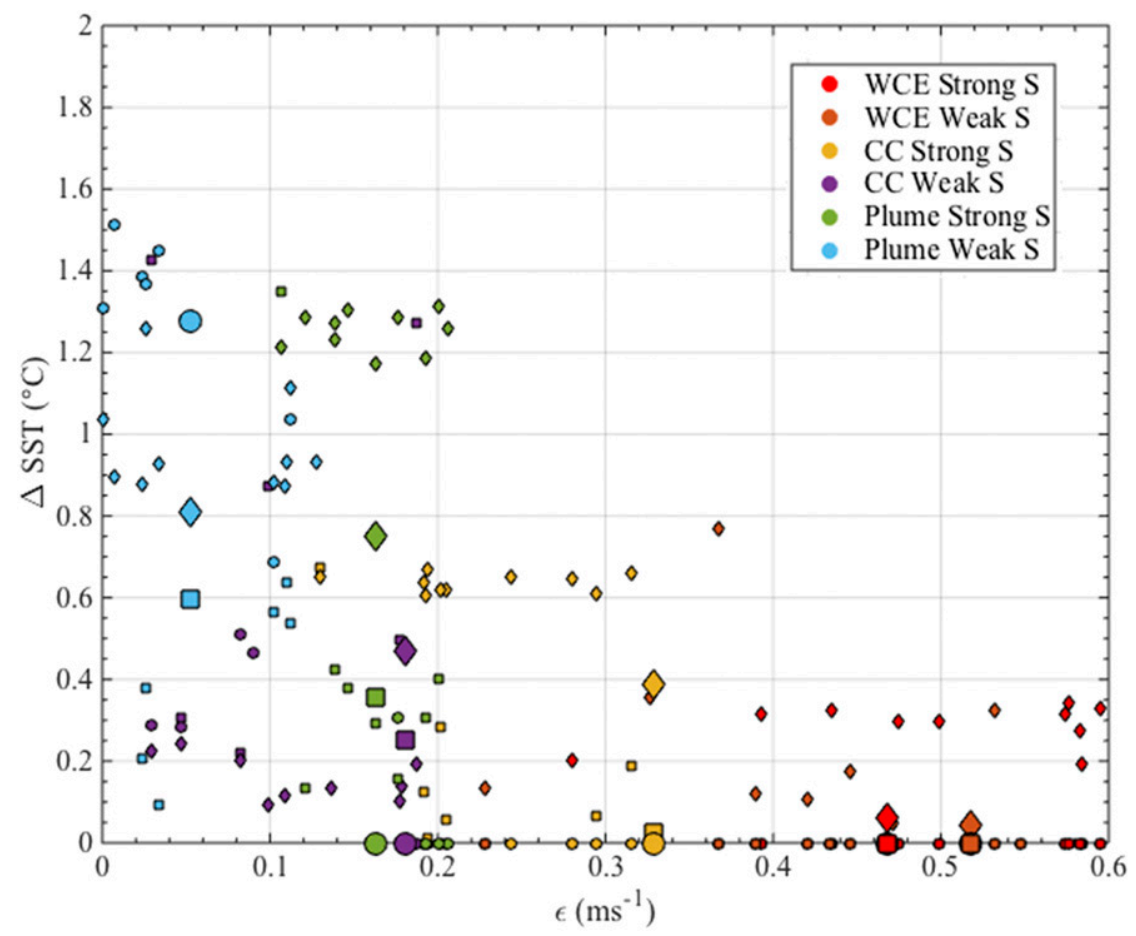

FIG. 4. The $\epsilon$ vs SST cooling for the different ocean regimes listed in Fig. 1 (large markers). The $\epsilon$ and SST cooling for randomly generated $T-S$ profiles (explained in main text) are indicated by the small markers. Circles represent values from the KT scheme, squares are values from the PRT scheme, and diamonds are values from the PWP scheme.

baroclinic wave speeds are a function of both thermal and haline regime, where deeper isothermal layers and/ or increased stratification result in larger values of $\epsilon$. This contextualizes findings in section 3 a such that stratification strength plays a role in SST response, but its importance depends on the background thermal structure. A scaling analysis (not shown) indicates that for deeper isothermal layers, $\epsilon$ is determined more by BLT/ ILD rather than density differences, whereas for shallow isothermal layers, $\epsilon$ is more dependent on density differences between the MLD and ILD. This also explains why the WCE experiments are not sensitive to either the inclusion of salinity or stratification strength whereas the PLUME experiments are sensitive to both.

Though the experiments in this study only consider a stationary wind forcing, the influence of BL salinity stratification on coupling between a passing TC and thermocline can still be speculated using $\mathrm{Fr}_{s}$. Including the influence of BL stratification would theoretically decrease the coupling between the sea surface and thermocline response during TC passage compared to that which does not consider the BL. For example, if $U_{h}=c=$ $2 \mathrm{~m} \mathrm{~s}^{-1}$, values of $\mathrm{Fr}_{s}$ for all regimes would be greater than 1 whereas Fr would be equivalent to 1 . This indicates a $\mathrm{TC}$ would encounter a baroclinic response in $\mathrm{BL}$ regions compared to a barotropic response in non-BL regions (Geisler 1970). Furthermore, values of $\mathrm{Fr}_{s}$ between the CC weak $S$ and PLUME strong $S$ regimes would be comparable for the same $U_{h}$ and $c$ criteria considering that $\epsilon$ for the two regimes is 0.18 and $0.16 \mathrm{~m} \mathrm{~s}^{-1}$, respectively. This indicates analogous coupling and SST responses in these two regimes and emphasizes the importance of salinity stratification in the PLUME $S$ regime as shown in section 3 a.

\section{Summary and conclusions}

The results of this study underscore the potential influence of salinity stratification on upper-ocean mixing and SST cooling during TC wind forcing and show the contributions of both vertical thermal and haline structure in these processes. The findings of this study are important since literature has shown that even modest differences in SST have a significant impact on air-sea heat exchange in a TC and TCs frequently pass over BL regimes in the tropical global oceans. In deep isothermal layers, the vertical salinity gradient does not contribute to SST cooling during TC wind forcing because the vertical thermal structure dominates. However, in shallow isothermal layers, SST cooling is sensitive to the vertical 
salinity gradient. SST cooling in a salinity-stratified environment is also sensitive to which ocean mixed layer (OML) scheme is chosen. KT processes result in the most SST cooling, although the scheme takes the longest to erode the BL; shear instability processes as in PWP erode the BL the fastest. These results are put into context through the creation of a BL baroclinic wave speed $\epsilon$, which modifies the Froude number. The $\epsilon$ emphasizes that the BL reduces the coupling between the thermocline and the sea surface response during TC wind forcing. It also highlights that salinity stratification becomes important for coupling when a TC interacts with relatively shallow isothermal layers. Overall, the results suggest that ocean mixed layer dynamical schemes need to be chosen wisely when modeling TCs over a salinity-stratified upper-ocean environment.

Acknowledgments. The corresponding author acknowledges the generous funding support by NASA (Grant NNX15AG43G) and the insightful suggestions from Dr. Benjamin Jaimes (RSMAS/UM).

\section{APPENDIX}

\section{Revisions to KT and PRT Models to Incorporate Salinity}

a. $K T$

The temperature tendency equation for $\mathrm{KT}$ is

$$
\frac{d T}{d t}=-\mathrm{r} \frac{w_{e} \Delta T}{h}
$$

where $Y$ enacts the second law of thermodynamics, $\Delta T$ is the temperature difference between the mean isothermal layer temperature and the mean thermocline temperature, and $h$ is equal to either the ILD ( $T$-only) or MLD $(T-S)$. The time evolution of $h$ is $h(t)=h_{0}+w_{e} d t$. The KT entrainment velocity for $T$-only experiments is

$$
w_{e}=\frac{c_{1} u_{*}^{3}}{\alpha h g \Delta T}+\frac{c_{2} Q}{\rho_{0} c_{p} \Delta T},
$$

whereas for the $T-S$ experiments

$$
w_{e}=\frac{c_{1} u_{*}^{3}}{g\left(\frac{\rho_{T}-\rho_{M}}{\rho_{0}}\right) h}+\frac{c_{2} Q}{\rho_{0} c_{p} \Delta T},
$$

where $c_{1}$ and $c_{2}$ are proportionality coefficients representing sources and sinks of TKE, set to 2.5 and 0.4 , respectively, based on Jacob et al. (2000); $c_{p}=4000 \mathrm{JC}^{-1} \mathrm{~kg}^{-1} ; \rho_{0}=$ $1025 \mathrm{~kg} \mathrm{~m}^{-3} ; u_{*}$ is surface friction velocity; $\alpha \sim 10^{-4}{ }^{\circ} \mathrm{C}^{-1}$; and $Q$ is total heat flux, set to 0 . Density is incorporated in Eq. (A3) via reduced gravity, where $\rho_{T}$ is the mean thermocline density and $\rho_{M}$ is the mean mixed layer density.

\section{b. $P R T$}

PRT and PWP use a two-dimensional wind stress of $\tau_{x}=\rho_{\text {air }} C_{D}|u| U_{10}$ and $\tau_{y}=\rho_{\text {air }} C_{D}|v| U_{10}$, where $u$ and $v$ are the $10-\mathrm{m}$ zonal and meridional velocity components and $\rho_{\text {air }}$ is the density of dry air.

The temperature tendency equation for PRT yields

$$
\frac{\partial(h T)}{\partial t}+\frac{\partial}{\partial t}\left(\frac{1}{2} \Gamma h^{2}\right)-\frac{Q}{\rho},
$$

where $\Gamma$ is the mean thermal lapse rate below the mixed layer.

PRT first estimates an initial stratification via the Brunt-Väisälä frequency $N^{2}$. The $T$-only formulation is

$$
N^{2}=\alpha g \Gamma \text {. }
$$

For $T-S$ experiments,

$$
N^{2}=-\frac{g}{\rho_{0}} \frac{\partial \rho}{\partial z} .
$$

Maximum $N^{2}$ at the base the mixed layer is used to estimate a "salinity equivalent" lapse rate $\Gamma_{s}$ for $T-S$ experiments in this scheme:

$$
\Gamma_{s}=\frac{N_{\max }^{2}}{\alpha g} .
$$

The $\alpha$ in Eq. (A6) is estimated as

$$
\alpha=-\frac{1}{\rho_{0}} \frac{\partial \rho}{\partial T}
$$

For both experiment types, mixed layer current components are initialized at 0 .

\section{REFERENCES}

Androulidakis, Y., V. Kourafalou, G. Halliwell, M. Le Hénaff, H. Kang, M. Mehari, and R. Atlas, 2016: Hurricane interaction with the upper ocean in the Amazon-Orinoco plume region. Ocean Dyn., 66, 1559-1588, https://doi.org/10.1007/s10236-016-0997-0.

Balaguru, K., P. Chang, R. Saravanan, L. R. Leung, Z. Xu, M. Li, and J.-S. Hsieh, 2012: Ocean barrier layers' effect on tropical cyclone intensification. Proc. Natl. Acad. Sci. USA, 109, 14 343-14 347, https://doi.org/10.1073/pnas.1201364109.

Chi, N.-H., R.-C. Lien, E. A. D'Asaro, and B. B. Ma, 2014: The surface mixed layer heat budget from mooring observations in the central Indian Ocean during Madden-Julian oscillation events. J. Geophys. Res. Oceans, 119, 4638-4652, https://doi.org/ 10.1002/2014JC010192. 
Cione, J. J., and E. W. Uhlhorn, 2003: Sea surface temperature variability in hurricanes: Implications with respect to intensity change. Mon. Wea. Rev., 131, 1783-1796, https://doi.org/10.1175//2562.1.

de Boyer Montegut, C., J. Mignot, A. Lazar, and S. Cravatte, 2007: Control of salinity on the mixed layer depth in the world ocean: 1. General description. J. Geophys. Res., 112, C06011, https://doi.org/10.1029/2006JC003953.

Geisler, J. E., 1970: Linear theory on the response of a two layer ocean to a moving hurricane. Geophys. Fluid Dyn., 1, 249-272, https://doi.org/10.1080/03091927009365774.

Grodsky, S. A., and Coauthors, 2012: Haline hurricane wake in the Amazon/Orinoco plume: AQUARIUS/SACD and SMOS observations. Geophys. Res. Lett., 39, L20603, https://doi.org/ 10.1029/2012GL053335.

Hernandez, O., J. Jouanno, and F. Durand, 2016: Do the Amazon and Orinoco freshwater plumes really matter for hurricaneinduced ocean surface cooling? J. Geophys. Res. Oceans, 121, 2119-2141, https://doi.org/10.1002/2015JC011021.

Jacob, S. D., L. K. Shay, A. J. Mariano, and P. G. Black, 2000: The 3D oceanic mixed layer response to Hurricane Gilbert. J. Phys. Oceanogr., 30, 1407-1429, https://doi.org/10.1175/ 1520-0485(2000)030<1407:TOMLRT>2.0.CO;2.

Jaimes, B., and L. K. Shay, 2009: Mixed layer cooling in mesoscale oceanic eddies during Hurricanes Katrina and Rita. Mon. Wea. Rev., 137, 4188-4207, https://doi.org/10.1175/2009MWR2849.1.

, - _ , and E. W. Uhlhorn, 2015: Enthalpy and momentum fluxes during Hurricane Earl relative to underlying ocean features. Mon. Wea. Rev., 143, 111-131, https://doi.org/ 10.1175/MWR-D-13-00277.1.

, ——, and J. K. Brewster, 2016: Observed air-sea interactions in tropical cyclone Isaac over Loop Current mesoscale eddy features. Dyn. Atmos. Oceans, 76, 306-324, https://doi.org/ 10.1016/j.dynatmoce.2016.03.001.

Kraus, E. B., and J. S. Turner, 1967: A one-dimensional model of the seasonal thermocline II. The general theory and its consequences. Tellus, 19, 98-106, https://doi.org/10.3402/tellusa.v19i1.9753.

Lukas, R., and E. Lindstrom, 1991: The mixed layer of the western equatorial Pacific Ocean. J. Geophys. Res., 96, 3343-3357, https://doi.org/10.1029/90JC01951.

McPhaden, M. J., and G. R. Foltz, 2013: Intraseasonal variations in the surface layer heat balance of the central equatorial Indian Ocean: The importance of zonal advection and vertical mixing. Geophys. Res. Lett., 40, 2737-2741, https://doi.org/10.1002/grl.50536.

Mignot, J., A. Lazar, and M. Lacarra, 2012: On the formation of barrier layers and associated vertical temperature inversions:
A focus on the northwestern tropical Atlantic. J. Geophys. Res., 117, C02010, https://doi.org/10.1029/2011JC007435.

Neetu, S., and Coauthors, 2012: Influence of upper-ocean stratification on tropical cyclone-induced surface cooling in the Bay of Bengal. J. Geophys. Res., 117, C12020, https://doi.org/ 10.1029/2012JC008433.

Pollard, R. T., P. B. Rhines, and R. O. R. Y. Thompson, 1973: The deepening of the wind-mixed layer. Geophys. Fluid Dyn., 3, 381-404, https://doi.org/10.1080/03091927208236105.

Powell, M., P. J. Vickery, and T. A. Reinhold, 2003: Reduced drag coefficient for high wind speeds in tropical cyclones. Nature, 422, 279-283, https://doi.org/10.1038/nature01481.

Price, J. F., R. A. Weller, and R. Pinkel, 1986: Diurnal cycling: Observations and models of the upper ocean response to diurnal heating, cooling, and wind mixing. J. Geophys. Res., 91, 8411-8427, https://doi.org/10.1029/JC091iC07p08411.

Reul, N., Y. Quilfen, B. Chapron, S. Fournier, V. Kurdyavtsev, and R. Sabia, 2014: Multisensor observations of the Amazon-Orinoco River plume interactions with hurricanes. J. Geophys. Res. Oceans, 119, 8271-8295, https://doi.org/10.1002/2014JC010107.

Rudzin, J. E., L. K. Shay, B. Jaimes, and J. K. Brewster, 2017: Upper ocean observations in eastern Caribbean Sea reveal barrier layer within a warm core eddy. J. Geophys. Res. Oceans, 122, 1057-1071, https://doi.org/10.1002/2016JC012339.

Shay, L. K., and E. Uhlhorn, 2008: Loop Current response to Hurricanes Isidore and Lili. Mon. Wea. Rev., 136, 3248-3274, https://doi.org/10.1175/2007MWR2169.1

—_, A. J. Mariano, S. D. Jacob, and E. H. Ryan, 1998: Mean and near-inertial ocean current response to Hurricane Gilbert. J. Phys. Oceanogr., 28, 858-889, https://doi.org/ 10.1175/1520-0485(1998)028<0858:MANIOC > 2.0.CO;2.

Sprintall, J., and M. Tomczak, 1992: Evidence of the barrier layer in the surface layer of the tropics. J. Geophys. Res., 97, 73057316, https://doi.org/10.1029/92JC00407.

Vissa, N. K., A. N. V. Satyanarayana, and B. P. Kumar, 2013: Response of upper ocean and impact of barrier layer on Sidr cyclone induced sea surface cooling. Ocean Sci. J., 48, 279-288, https://doi.org/10.1007/s12601-013-0026-x.

Wang, X., G. Han, W. Qi, and W. Li, 2011: Impact of barrier layer on typhoon-induced sea surface cooling. Dyn. Atmos. Oceans, 52, 367-385, https://doi.org/10.1016/j.dynatmoce.2011.05.002.

Yan, Y., L. Li, and C. Wang, 2017: The effects of oceanic barrier layer on the upper ocean response to tropical cyclones. J. Geophys. Res. Oceans, 122, 4829-4844, https://doi.org/ 10.1002/2017JC012694. 